\title{
Immobilization of Elk, Cervus elaphus, with Telezol and Xylazine and Reversal with Tolazine or Yohimbine
}

\author{
RICK RosATTE
}

Ontario Ministry of Natural Resources, Wildlife Research and Development Section, Trent University, DNA Building, 2140 East Bank Drive, Peterborough, Ontario K9J 7B8 Canada; e-mail: rick.rosatte@ ontario.ca.

Rosatte, Rick. 2007. Immobilization of Elk (Cervus elaphus) with telezol and xylazine and reversal with tolazine or yohimbine. Canadian Field-Naturalist 121(1): 62-66.

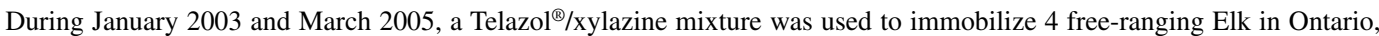
Canada. A dosage of 3.3-3.6 mg/kg of Telazol ${ }^{\circledR}$ and $1.7-2.0 \mathrm{mg} / \mathrm{kg}$ of xylazine proved to be effective for the rapid immobilization of Elk. Induction time for those dosages was as short as 3-4 minutes. The advantage of using Telazol ${ }^{\circledR}$ is that only small volumes (3-4 ml) are needed to immobilize Elk-sized animals. In addition, Tolazine ${ }^{\circledR}$ and yohimbine both proved to be effective antagonists for xylazine with recovery times of 8 to 15 minutes when administered at dosages of 3.3-3.6 and $0.08-0.14 \mathrm{mg} / \mathrm{kg}$, respectively. The use of oxygen proved to be effective for treatment of hyoxemia in Elk immobilized with

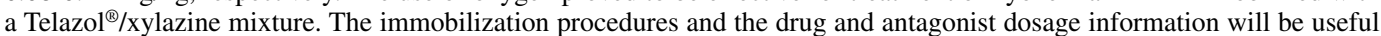
to researchers planning to capture free-ranging Elk for activities such as radio-collaring and blood sampling.

Key Words: Cervus elaphus, Elk, antagonist, immobilization, reversal agent, Telazol ${ }^{\circledR}$, Tolazine, Yohimbine, Ontario.

During 1998 - 2001, 443 Elk (Cervus elaphus), also known as American Elk, or Wapiti, were transported from Elk Island National Park (EINP), Alberta, and released in four areas of Ontario, Canada (Bellhouse and Rosatte 2005; Rosatte et al. 2007). One of the release sites, near Bancroft, Ontario (approximately $44^{\circ} 5^{\prime} \mathrm{N}, 77^{\circ} 30^{\prime} \mathrm{W}$ ), received 120 Elk during 2000 and 2001. All Elk were aged and weighed at EINP during processing, which included ear-tagging and fitting the Elk with telemetry collars (VHF and GPS) (Rosatte et al. 2002). The weights of Elk at EINP were used as guidelines to estimate the weight of Elk in Ontario for drug dosage calculations.

As ten of the Elk were fitted with GPS collars during processing at EINP, some of the animals had to be immobilized to retrieve the collars and download the data. On 16 January $2003\left(-20^{\circ} \mathrm{C}\right)$, an 8 year old, freeranging adult cow Elk (ear tag 341), previously fitted with a GPS collar (148.188 Mhz) at EINP, Alberta, was immobilized with Telazol ${ }^{\circledR}$ (tiletamine hydrochloride and zolazepam hydrochloride) (Fort Dodge Animal Health, Fort Dodge, Iowa) and AnaSed (xylazine hydrochloride) (Vet-A-Mix, Shenandoah, Iowa) near Bancroft, Ontario, for the purpose of collar removal. The drug dosage (target dosage was about $3 \mathrm{mg} / \mathrm{kg}$ Telazol ${ }^{\circledR}$ and approximately $1.5 \mathrm{mg} / \mathrm{kg}$ of xylazine) was calculated using an estimated weight for the Elk of $236 \mathrm{~kg}$ - her weight during processing at EINP in January 2001 . The immobilizing drug mixture was prepared by injecting the desired volume and weight of xylazine into a bottle containing lyophilized Telazol ${ }^{\circledR}$.

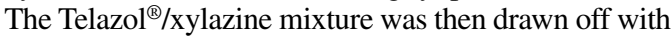
a syringe and injected into the immobilization dart. The dart was then plugged with vasoline to prevent the leakage of drugs from the dart. A Model 193 Pneu-Dart 50 caliber rifle and $4 \times$ scope (Pneu-Dart Inc., Williams- port, Pennsylvania) with a yellow CCI 22 caliber brass power charge (Omaha Industries, Lewiston, Idaho) and a diffuser setting of 4 , was used to project a 50 caliber, $4 \mathrm{cc}$ aluminum type $\mathrm{C}$ dart with a $3 \mathrm{~cm}$ long barbed needle (Pneu-Dart Inc., Williamsport, Pennsylvania), that contained the Telazol ${ }^{\circledR} / x y l a z i n e ~ m i x t u r e$, into the hind leg musculature of the Elk. The distance of the shot was about $35 \mathrm{~m}$. As soon as the animal was in a lateral recumbent position and there was no evidence of leg or eye reflex, she was moved into a sternal recumbent position and the head was elevated to minimize the chance of bloat and regurgitation of rumen contents. Ophthalmic ointment was applied to the eyes of the immobilized Elk to prevent drying. The respiration rate of the cow Elk was about $18 / \mathrm{min}$ at $30 \mathrm{~min}$ post-darting. At $36 \mathrm{~min}$ post-darting, the respiration rate increased to $54 / \mathrm{min}$ and breathing was very shallow. At this point, bloat was evident and the $\mathrm{gum} /$ tongue area was blue in color (indicative of low oxygen content in the blood). The animal was administered oxygen orally as a treatment for hypoxemia, as well as rolled side to side in an effort to relieve the bloat. The head was elevated and lowered as well to stimulate belching. At 50 min post darting, respiration rate decreased to $42 / \mathrm{min}$ and the tongue/gum area returned to a pinkish color following the administration of oxygen. Hibitane antibacterial veterinary ointment ( $1 \%$ chlorhexidine acetate) (Ayerst, Guelph, Ontario) was applied to the dart wound. After the animal was processed an intramuscular injection of Tolazine (tolazoline hydrochloride, Lloyd Laboratories, Shenandoah, Iowa) was administered in the right leg musculature to speed recovery. The concentration and dosage of drugs as well as the induction, down and recovery times are shown in Table 1. After the animal was in a standing position, she orally expelled gas for several 
seconds and the bloat decreased dramatically. The Elk was monitored for the next few days and no adverse effects were noted. She was still in good health when observed near Bancroft, Ontario in April 2005.

On 19 February $2004\left(-6^{\circ} \mathrm{C}\right)$, a 10.5 year old cow Elk (ear tag 360) was immobilized near Bancroft, Ontario, to remove a GPS collar (149.560 Mhz). The weight of the animal at EINP during January 2001 was $234 \mathrm{~kg}$. The animal was darted with a mixture of Tela$\mathrm{zol}^{\circledR} / \mathrm{xylazine}$ as described above using a Pneu-Dart rifle, with a yellow 22 caliber power charge and a diffuser setting of 3 , and a $4 \mathrm{cc}$ dart. The distance of the shot was about $25 \mathrm{~m}$ with the dart hitting the right upper hind leg musculature. As the drug took effect the Elk assumed a recumbent position beginning with the hind end first (Figure 1). Some bloat was evident so oxygen was administered for treatment of hypoxemia and the animal was rolled from side to side and the head elevated to expel gases (Figure 2). Respiration rate increased from about 14/min to 70/min when bloating occurred. The gums and tongue remained pink colored throughout the handling period. When processing was complete, Tolazine was injected intramuscularly to reverse the effects of xylazine and speed recovery from the drug. Induction, immobilization and recovery times are noted in Table 1.

On 11 January $2005\left(-17^{\circ} \mathrm{C}\right.$ ambient temperature), a yearling bull Elk, born in Ontario, suspected of being infected with meningeal worm (Parelaphostrongylus tenuis), was immobilized with an intramuscular injection of Telazol ${ }^{\circledR}$ and xylazine hydrochloride for the purpose of collecting a blood sample. The dosage of drug was calculated using mean weights of yearling bull Elk at EINP. As the Elk had no fear of humans, possibly due to the effects of $P$. tenuis, the drugs were administered intramuscularly in the right upper hind limb area via a $5 \mathrm{cc}$ sterile syringe (Burron Medical Products, Bethlehem, Pennsylvania, USA) and $22 \mathrm{~g}$ $(4 \mathrm{~cm})$ needle (Terumo, Belgium) attached to a jab stick made from a piece of copper tubing. When processing was complete, which included radio-collaring (148.412 Mhz) and ear-tagging (\#139) (as reported in McIntosh et al. 2007), the Elk was injected intramuscularly in the hind limb musculature with Yobine (yohimbine hydrochloride) (Lloyd Laboratories, Shenandoah, Iowa, USA) as a reversal agent for xylazine. Drug dosages, induction, immobilization and recovery times are presented in Table 1. While immobilized, respiration rate for the yearling bull Elk was 14-16/min, there was no evidence of bloat, and the gums and tongue remained pink in color.

On 30 March $2005\left(+5^{\circ} \mathrm{C}\right.$ ambient temperature), a $2 \frac{1}{2}$ year old bull Elk (born in Ontario) was immobilized with Telazol ${ }^{\circledR}$ and xylazine for the purpose of de-antlering as the animal had broken the pedicle in the fall of 2004. The drugs were administered as described above using a Pneu-Dart rifle, with a green 22 caliber power charge, a diffuser setting of 5 , and a $4 \mathrm{cc}$ dart. The distance of the shot was about $30 \mathrm{~m}$ with the dart hitting

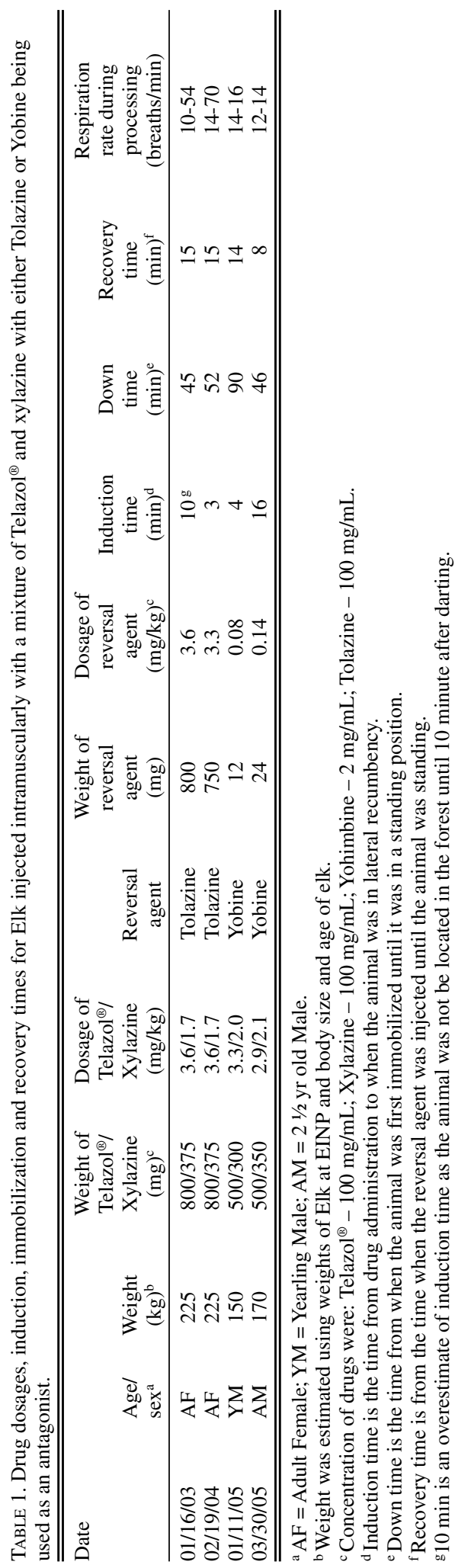




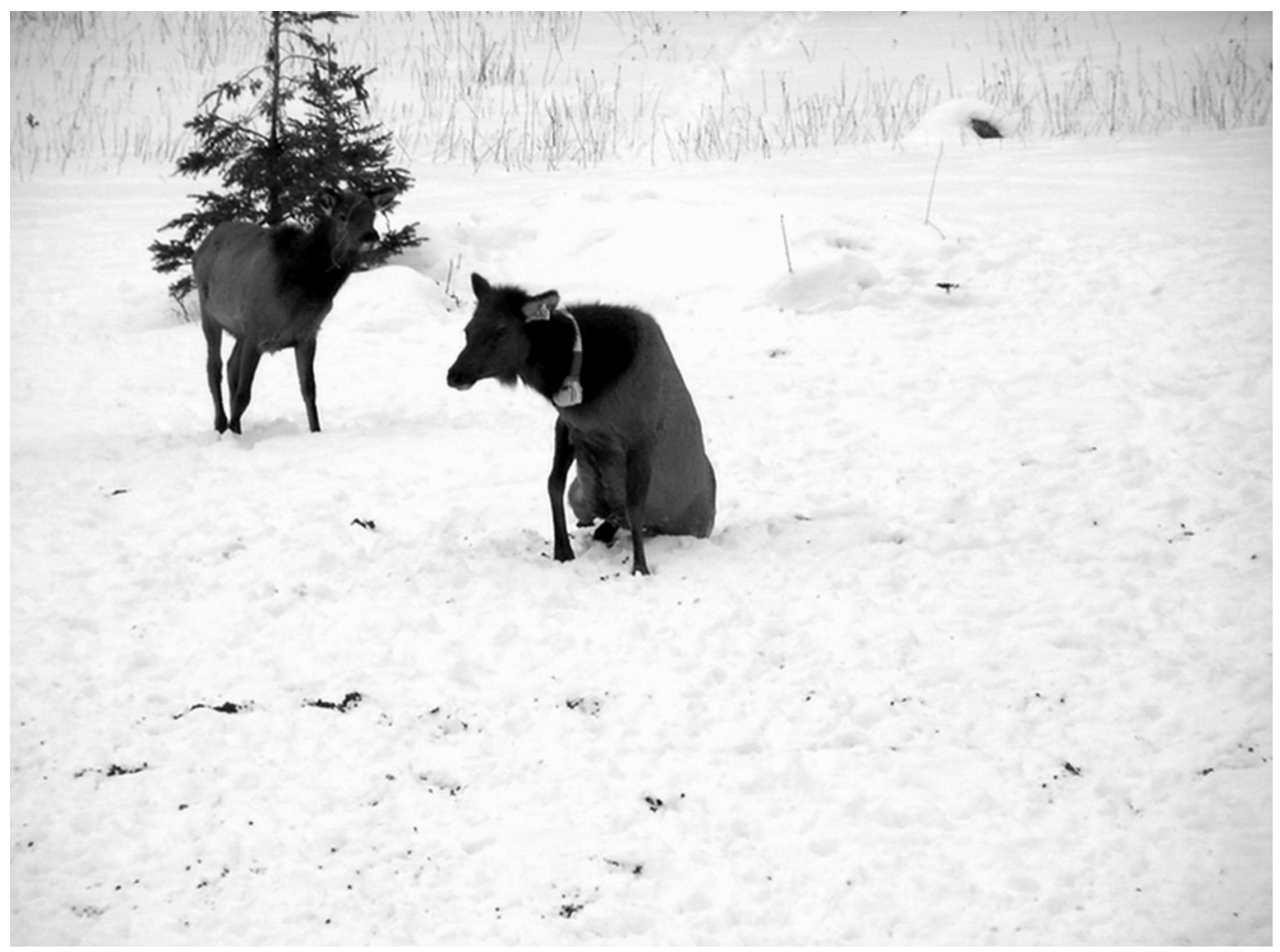

FIGURE 1. A GPS collared adult cow Elk (ear-tag 360) exhibiting hind limb paralysis 2 minutes after being darted with a mixture of Telazol ${ }^{\circledR}$ and Xylazine. (Photo by R. Rosatte).

the right upper hind leg musculature. Respiration rate was stable at about $12 / \mathrm{min}$ during processing (deantlered and ear-tagged - \#141) and the gums and tongue remained pink colored with no evidence of hypoxemia or bloat. A $3 \mathrm{cc}$ intramuscular injection of Dystosel (Vitamin E - $136 \mathrm{IU} / \mathrm{mL}$ and selenium - 3 $\mathrm{mg} / \mathrm{mL}$ ) (Pfizer Canada Inc, London, Ontario) was administered as a preventative measure against capture myopathy. When processing was complete, Yobine was injected intramuscularly to speed recovery from the effects of xylazine. Induction, immobilization and recovery times are shown in Table 1 .

\section{Discussion}

A dosage of 3.3-3.6 mg/kg (body weight) of Tela$\mathrm{zol}^{\circledR}$ and $1.7-2.0 \mathrm{mg} / \mathrm{kg}$ of xylazine proved to be an effective drug combination for the rapid immobilization of four free-ranging Elk in Ontario. Induction time or the time from darting until the animal was prone for those dosages was 3-4 minutes. This calculation did not include the Elk for which induction time was noted as 10 minutes, as that animal was not immediately located in the forest. Similarly, Millspaugh et al. (1995) reported a mean induction time of 4.6 minutes when Elk were immobilized with $2.5 \mathrm{mg} / \mathrm{kg}$
Telazol ${ }^{\circledR}$ and $0.3 \mathrm{mg} / \mathrm{kg}$ xylazine. The advantage of

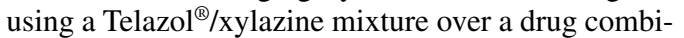
nation such as ketamine hydrochloride (at a commercially available concentration $100 \mathrm{mg} / \mathrm{mL}$ )/xylazine is that a much lower volume of Telazol is required to attain a state of immobilization. For example, only a $4 \mathrm{~mL}$ (800 mg of Telazol ${ }^{\circledR}$ reconstituted in $3.5 \mathrm{~mL}$ of xylazine) volume of drug was required to immobilize a $225 \mathrm{~kg}$ cow Elk. About $15 \mathrm{~mL}$ of a ketamine hydrochloride/xylazine hydrochloride (100 mg/mL ketamine) mixture was required to immobilize a bull Elk in Ontario during 2003. The advantage of a smaller volume

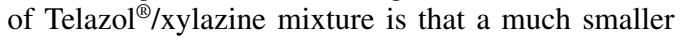
dart can be used $(4 \mathrm{cc}$ compared to a 10 or $15 \mathrm{cc}$ ) to administer the drugs, which means less weight and less damage to the animal when the dart is administered via an immobilization gun. A smaller dart $(4 \mathrm{cc})$ has a better trajectory and is more accurate at longer distances $(>65 \mathrm{~m})$ than a larger/heavier dart $(10-15 \mathrm{cc})$. In addition, as the induction time for ketamine in Elk is generally longer than that for Telazol ${ }^{\circledR}$, animals tend to move farther before being completely immobilized (Golightly and Hofstra 1989; Miller et al. 2004), which could result in problems locating the animal in heavily forested areas. 

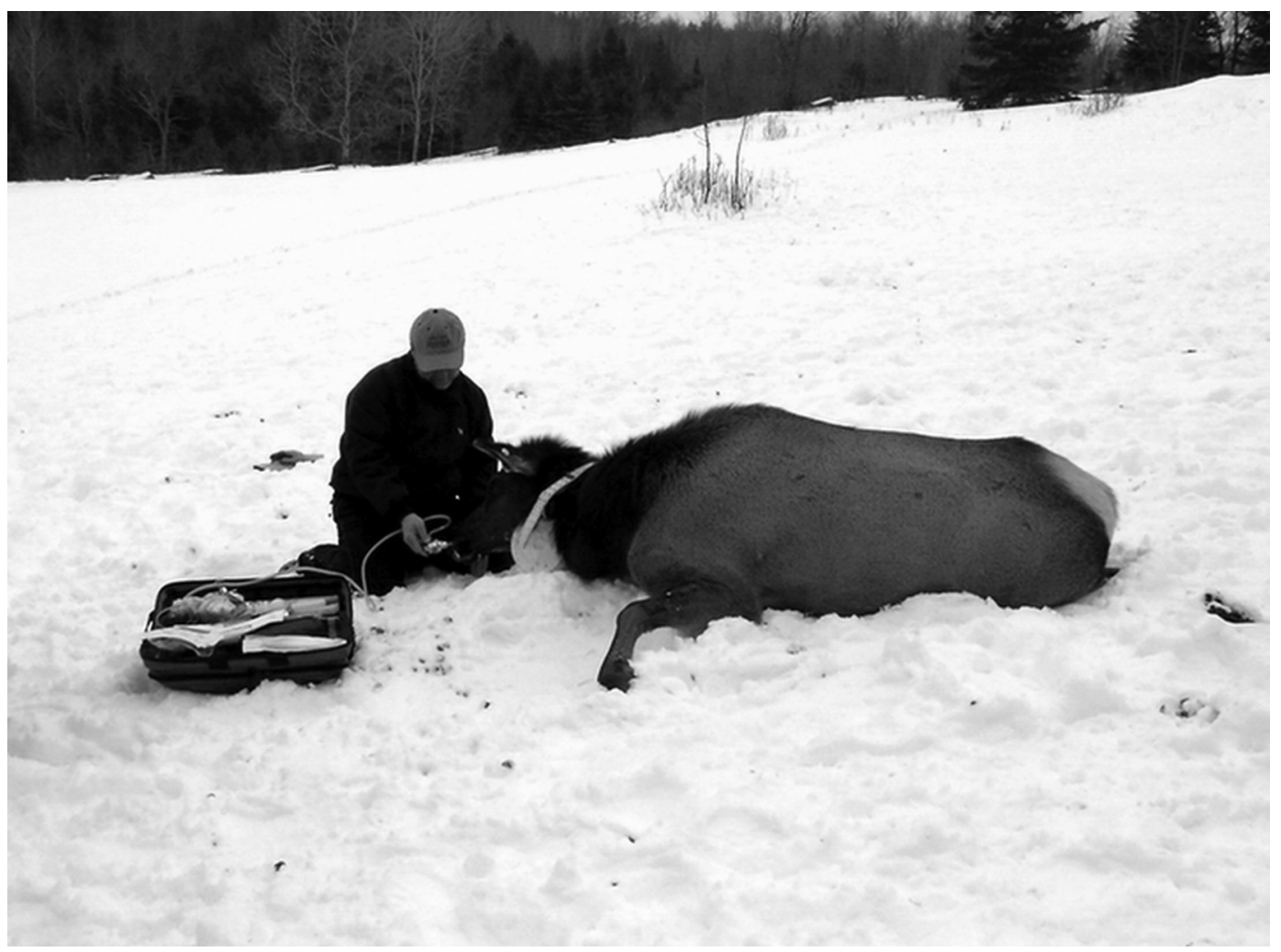

FIGURE 2. Oxygen being administered to the immobilized cow Elk (ear tag 360) for treatment of hypoxemia (Photo by R. Rosatte).

One drawback with using a Telazol ${ }^{\circledR} / x$ lazine mixture for the immobilization of Elk is the extended recovery time which could lead to decreased survival. In one study, an Elk immobilized with a Telazol ${ }^{\circledR} / x y l a z i n e$ mixture was not administered an antagonist and was immobilized for 5 hours (Golightly and Hofstra 1989). As well, there is no known antagonist for the tiletamine component of Telazol ${ }^{\circledR}$ (Miller et al. 2004). Tolazine and yohimbine both proved to be effective antagonists for xylazine with recovery times of 8 to 15 minutes when administered at dosages of 3.3-3.6 and 0.08$0.14 \mathrm{mg} / \mathrm{kg}$ (body weight), respectively. However, the key to rapid recovery was administering the antagonist 45-60 minutes (or longer) post -immobilization. This allowed sufficient time for Telazol ${ }^{\circledR}$ to be metabolized and diminish side-effects after injection of the reversal agent. Animals may stagger for some time due to the effects of Telazol ${ }^{\circledR}$ if the antagonist is administered too soon after immobilization as the antagonist only neutralizes the effects of xylazine. Millspaugh et al. (1995) reported a mean recovery time of 14 minutes when yohimbine was administered intravenously to reverse xylazine administered to Elk at a dose of $0.3 \mathrm{mg} / \mathrm{kg}$ (in a mixture with Telazol ${ }^{\circledR}$ at a dose of $2.5 \mathrm{mg} / \mathrm{kg}$ ). However, a recovery time in that study of
125 min was reported when yohimbine was given intramuscularly.

Hypoxemia or deficient oxygenation of the blood may occur during the immobilization of wild ruminants. This can lead to organ failure and capture myopathy (Read et al. 2001). Bloating occurred in two of the Elk immobilized in this study despite their being in a sternal recumbent position. As well, respiration rate was high in those two Elk \{normal respiration rate for elk is about 13 breaths/min (Hudson and Haigh 2002) \}. Bloat is a result of gas production in the rumen, which may result in pressure being applied to the diaphragm (due to the weight of the abdominal viscera on the diaphragm) with resultant respiratory/circulatory problems and oxygen depletion in the blood. Bloating in this study may have been aggravated due to the animals foraging at feeding stations (with alfalfa) prior to darting. Oxygen quickly relieved the symptoms of hypoxemia (blue tongue, lips), and the suggested rate of oxygen administrated nasally for preventing hypoxemia was $10 \mathrm{~L} / \mathrm{min}$ for a period of about 5 minutes (Read et al. 2001)

The four immobilized Elk were later (1 month to 2 years) located by radio-telemetry and had recovered fully, with no observable side effects from immobiliza- 
tion or handling. Capture procedures, drugs and antagonist data outlined above will be useful to researchers planning to capture free-ranging Elk. For "off-label" use of the above drugs on wild animals such as Elk, an "Emergency Drug Release Authorization" must be approved by the Veterinary Drugs Directorate, Health Canada, and animals immobilized with agents such as Telazol ${ }^{\circledR}$ are not to be used as food items.

\section{Acknowledgments}

The Ontario Elk Restoration program is supported by the Provincial Elk Technical Team and the Ontario Ministry of Natural Resources (OMNR), Wildlife Section, and the Wildlife Research and Development Section (WRDS). Thanks to Tom Simpson and Mike Scafie, OMNR, Bancroft District; John O'Donnell, Barry Wannamaker, Ryan Cavanaugh, Jason Langis, Bancroft Elk Program; Jim Young, Provincial Elk Program Coordinator; and Terese McIntosh and Arthur Dupuis, Trent University, for assisting with the immobilization and processing of the elk. Special thanks to Joe Neuhold for all of his assistance and dedication to the Elk Program. Thanks to Norm Cool and Rob Kay, Parks Canada, EINP, Alberta, and Bruce Chisholm, Canadian Food Inspection Agency, Edmonton, Alberta, for weighing and aging the elk during processing at EINP. J. C. Davies and Mike Allan, OMNR, WRDS, reviewed the manuscript and provided helpful comments.

\section{Literature Cited}

Bellhouse T., and R. Rosatte. 2005. Assessment of the potential for negative interaction between re-introduced elk ( $\mathrm{Cer}$ vus elaphus) and resident white-tailed deer (Odocoileus virginianus) in their wintering areas in Ontario, Canada. Mammalia 69 (1): 35-56.
Golightly R., and T. Hofstra. 1989. Immobilization of elk with a ketamine-xylazine mix and rapid reversal with yohimbine hydrochloride. Wildlife Society Bulletin 17: 5358.

Hudson R., and J. Haigh. 2002. Physical and physiological adaptations. Pages 199-257 in North American elk, ecology and management. Edited by D. Toweill and J. W. Thomas. Smithsonian Institution Press, Washington, D.C.

McIntosh, T., R. Rosatte, D. Campbell, K. Welch, D. Fornier, M. Spinato, and O. Ogunremi. 2007. Evidence of Parelaphostrongylus tenuis infections in free-ranging elk (Cervus elaphus) in southern Ontario. Canadian Veterinary Journal 48: 1146-1154.

Miller B., L. Muller, T. Doherty, D. Osborn, K. Miller, and R. Warren. 2004. Effectiveness of antagonists for tiletamine-zolazepam/xylazine immobilization in female whitetailed deer. Journal of Wildlife Diseases 40: 533-537.

Millspaugh J., G. Brundige, J. Jenks, C. Tyner, and D. Hustead. 1995. Immobilization of Rocky Mountain elk with Telazol and xylazine hydrochloride, with antagonism by yohimbine hydrochloride. Journal of Wildlife Diseases 31: 259-262.

Read M., N Caulkett, A. Symington, and T. Shury. 2001. Treatment of hypoxemia during xylazine-tiletaminezolazepam immobilization of wapiti. Canadian Veterinary Journal 42: 861-864.

Rosatte R., J. Hamr, B. Ranta, J. Young, and N. Cool. 2002. Elk restoration in Ontario, Canada: infectious disease management strategy, 1998-2001. Annals of the New York Academy of Sciences 969: 358-363.

Rosatte, R., J. Hamr, J. Young, I. Filion, and H. Smith. 2007. The restoration of Elk (Cervus elaphus) in Ontario, Canada: 1998-2005. Restoration Ecology 15: 34-43.

Received 19 January 2006

Accepted 11 January 2008 